\title{
Analysis of loss distribution of Conventional Boost, Z-source and Y-source Converters for wide power and voltage range
}

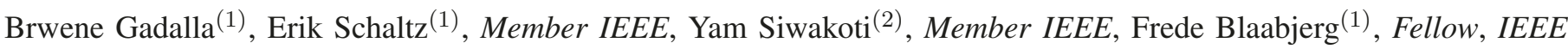 \\ Department of Energy Technology, Aalborg University ${ }^{(1)}$ \\ Aalborg 9220, Denmark \\ Department of Electrical, Mechanical and Mechatronic Systems, University of Technology Sydney ${ }^{(2)}$ \\ Sydney, Australia \\ bag@et.aau.dk, esc@et.aau.dk, Yam.Siwakoti@uts.edu.au, fbl@et.aau.dk
}

\begin{abstract}
Boost converters are needed in many applications which require the output voltage to be higher than the input voltage. Recently, boost type converters have been applied for industrial applications, and hence it has become an interesting topic of research. Many researchers proposed different impedance source converters with their unique advantages as having a high voltage gain in a small range of duty cycle ratio. However, the thermal behaviour of the semiconductor devices and passive elements in the impedance source converter is an important issue from a reliability point of view and it has not been investigated yet. Therefore, this paper presents a comparison between the conventional boost, the Z-source, and the Y-source converters based on a thermal evaluation of the semiconductors. In addition, the three topologies are also compared with respect to their efficiency. In this study the results show that the boost converter has higher efficiency than the $\mathrm{Z}$ source and Y-source converter for these specific voltage gain of 2 and 4 . The operational principle, mathematical derivations, simulation results and final comparisons are presented in this paper.

Key words- boost converter; Z-source converter; Y-source converter; winding losses; core losses; gain; thermal design; reliability
\end{abstract}

\section{INTRODUCTION}

B OOST type converters are essentially needed for many renewable energy applications such as Photo Voltaic (PV), Wind Turbine (WT) and automotive applications (electric and hybrid vehicles) as these often have lower input voltage than the required load voltage. In conventional boost converters, the demanded voltage gain normally requires higher duty cycle (sometimes close to unity), which leads to high conduction losses, higher voltage and current stresses on the switching devices. However, the aforementioned stressor factors may critically affect the reliability and the lifetime of the power electronic components. According to a review based on condition monitoring for device reliability in power electronic systems presented in [1], semiconductor and soldering failures in device modules are sharing totally $34 \%$ of converter system failures in Fig. 1. In today's perspective toward the reliability assessment of power electronic components and systems, three main aspects should be considered as shown in Fig. 2 [2].

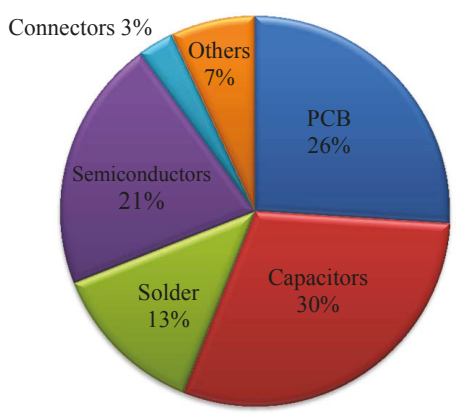

Fig. 1. Ranking and failure distrbution of power electronic components in power converters [1]

The design and verification aspect could be related to cover the aforementioned shortcomings in the conventional boost converter shown in Fig. 3. Both Z-source and Y-source as shown in Fig. 4 and Fig. 5 converters were proposed by the researchers as impedance source network converters to compromise the high voltage gain with small duty cycle ratio. Due to their flexibility for a wide voltage ranges and power conversions (DC-DC, DC-AC, AC-AC, and DC-AC) [8], various types of impedance source networks were reported as a solution to overcome the limitations of the voltage source inverter VSI, current source inverter CSI and some of the conventional uni/bi - directional converters [9].

Moreover, an important advantage of the impedance net- 


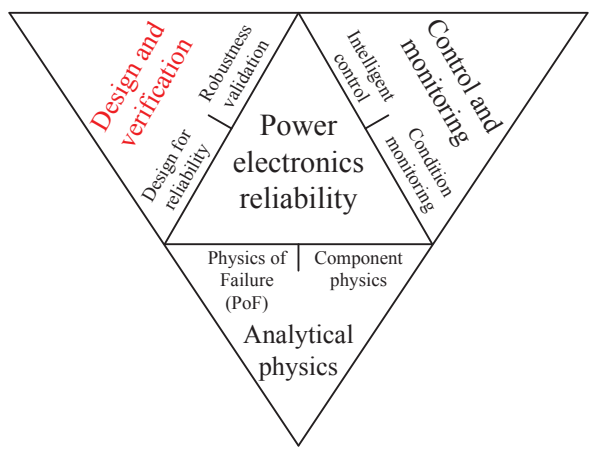

Fig. 2. Aspects in power electronics reliability assessment [2].

works is the small duty cycle ratio, which reduces the losses of the switch [10]. Therefore, many new topologies are proposed with each being claimed to have improved performances [8]. At present, a collective investigation of some of the existing boosting converters has not been initiated especially with reference to their thermal and reliability issues. Furthermore, an investigation of the Y-source converter from the point of view of thermal performance at high power ratings has not been reported as well. The junction temperature is one of the important factors that is affecting the thermal performance of the converter, and also the reliability [11].

In this paper the conventional boost, Z-source and Y-source converters are compared in terms of their efficiencies and junction temperature with respect to a wide power range, different voltage gains and assuming a constant ambient temperature. Moreover, calculations of all the relevant losses (e.g switching and conduction losses) of the power switching devices during the operation is also considered in the comparison [12].

This paper conducts a comprehensive investigation of the mapping of the losses of the power converter. Section II is focusing on the theory of operation and design of each converter. Section III describes the evaluation of the power losses and thermal performance of the three converters. Section IV describes the simulation results and discuss the results. Finally, the conclusion is given in section V.

\section{CONVERTER DESIGN AND THEORY OF OPERATION}

In this section the theory of operation of the converters and design formulas are presented.

\section{A. Conventional boost converter}

A boost converter is a step-up converter converting the voltage from low input voltage to higher voltage requiring a duty cycle $(0<\mathrm{D}<1)$. Thus its simple theory of operation as well as component count wise allows it to be a competitor with other boosting converters. The basic structure of the boost converter circuit, the equivalent circuit for on state mode of operation and off state mode of operation are shown in Fig. 3. It compromise of one active switch $\mathrm{SW}$, a diode $D_{1}$, an inductor $L_{1}$, and a capacitor $C_{1}$ for introducing a high voltage boost with $(\mathrm{D}>0.5)$. The two modes of operation are as following:

a) During the on-state: the switch is closed, the current flows through the inductor and store the energy in a magnetic field.

b) During the off-state: the switch is open, the current passed will be reduced as the voltage across the inductor is reversed and the magnetic field previously created will decrease to maintain the current flow to the load and the current through the diode will charge the capacitor giving a higher voltage.

The input/output voltage relationship is expressed in (1) as:

$$
V_{\text {out }}=\frac{V_{\text {in }}}{1-D}
$$

where $V_{\text {out }}$ is the output voltage, $V_{\text {in }}$ is the input voltage and $D$ is the duty cycle needed for the required voltage gain [13].

\section{B. Z-source converter}

The Z-source converter (ZSC) is a very convenient topology in many alternative energy sources and other different applications [3, 4]. The ZSC has the capability of ideally giving an output voltage range from zero to infinity regardless of the input voltage. The Z-Source converter circuit, and its two modes of operation are shown Fig.4. It consists of two inductors $\left(L_{1}, L_{2}\right)$ and two capacitors $\left(C_{1}, C_{2}\right)$ connected in $\mathrm{X}$ shape to be coupled to the dc voltage source. The ZSC can produce a required dc output voltage regardless of the input dc source voltage. The two modes of operation are as the following:

a) In the on-state: the switch is closed and the impedance capacitors $\left(C_{1}, C_{2}\right)$ release energy to the inductors $\left(L_{1}, L_{2}\right)$ and then the voltage source and the load will disconnect the Z-source network due to the turn off of the diodes $\left(D_{1}, D_{2}\right)$. The major concern is the large conduction current passing through the switch during the on state, which may decrease the converter efficiency.

b) In the off-state: the switch is opened and the input voltage will supply energy to the load through the two inductors as well as add energy to the two capacitors to compensate the energy lost during the on state.

The input/output voltage relationship is expressed in (2) as:

$$
V_{\text {out }}=\frac{V_{\text {in }}}{1-2 D}
$$

where $V_{\text {out }}$ is the output voltage, $V_{\text {in }}$ is the input voltage and $D$ is the duty cycle needed for the required voltage gain $[3,4]$.

\section{Y-source converter}

The Y-source converter is a promising topology for higher voltage gain in a small duty ratio and has a very wide range 


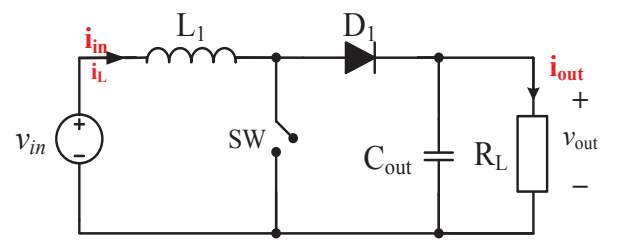

(a)

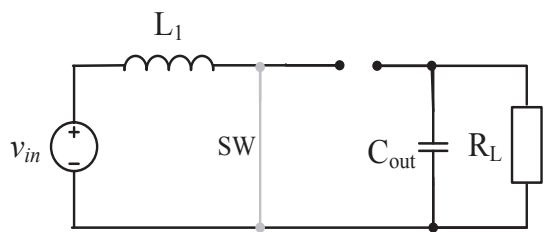

(b)

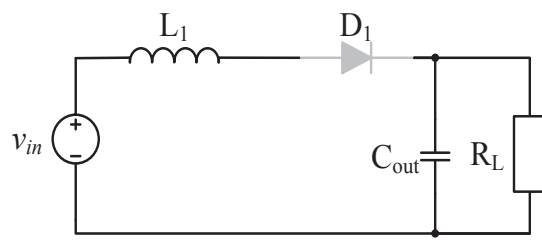

(c)

Fig. 3. a) Boost converter Circuit topology. b) Equivalent circuit for on state. c) Equivalent circuit for off state [13].

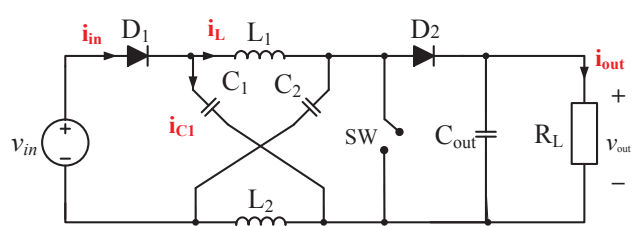

(a)

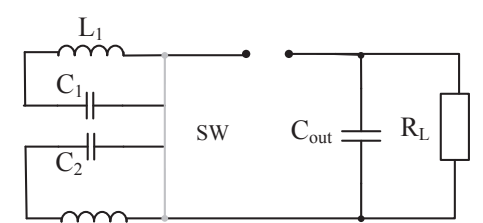

(b)

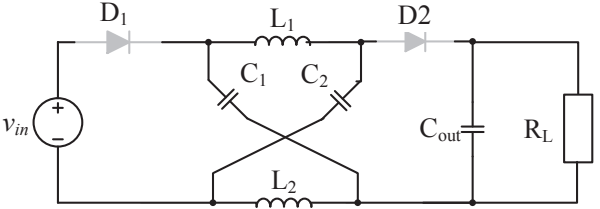

(c)

Fig. 4. a) Z-Source converter Circuit topology. b) Equivalent circuit for on state. c) Equivalent circuit for off state [3, 4].

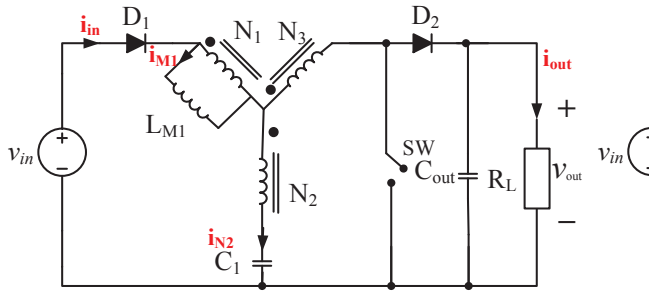

(a)

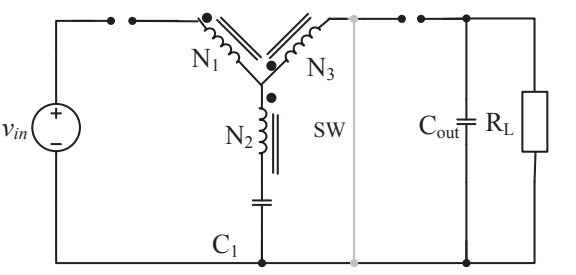

(b)

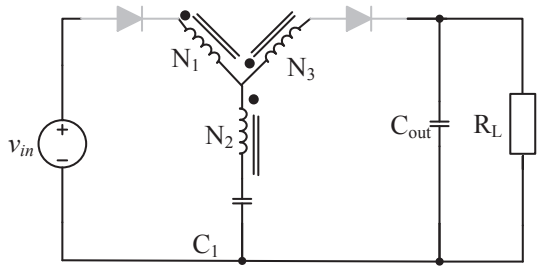

(c)

Fig. 5. a) Y-source converter Circuit topology. b) Equivalent circuit for on state. c) Equivalent circuit for off state [5-7].

of adjusting the voltage gain [5-7]. The range of duty cycle in the Y-source is narrower than the Z-source and the boost converter. Fig. 5 shows the Y-source impedance network and its two modes of operation. It is realized by a three-winding coupled inductor $\left(N_{1}, N_{2}\right.$, and $\left.N_{3}\right)$ for introducing the high boost at a small duty ratio for the SW. It has an active switch $\mathrm{SW}$, two diodes $\left(D_{1}, D_{2}\right)$, a capacitor $C_{1}$, and the windings of the coupled inductor are connected directly to SW and $D_{1}$, to ensure a very small leakage inductance at its winding terminals. The two modes of operation are as the following:

a) In the on-state: the switch is closed, $D_{1}$ and $D_{2}$ are off causing the capacitor $C_{1}$ to charge the magnetizing inductor of the coupled transformer and capacitor $C_{2}$ discharge to power the load.

b) In the off-state: the switch is opened, $D_{1}$ starts to conduct causing the input voltage to recharge the capacitor $C_{1}$ and the energy from the supply and the transformer will also flow to the load. When $D_{2}$ starts conducting, it recharges $C_{2}$ and the load is to be continuously powered.
The input/output voltage relationship is expressed in (3) as:

$$
V_{\text {out }}=\frac{V_{\text {in }}}{1-K D}
$$

where $V_{\text {out }}$ is the output voltage, $V_{\text {in }}$ is the input voltage, $D$ is the duty cycle [5-7] and $K$ is the winding factor. The winding factor $K$ is calculated according to the turns ratio of the three-winding coupled inductor and it is expressed in (4) as:

$$
K=\frac{N_{1}+N_{3}}{N_{3}-N_{2}}
$$

where $\left(N_{1}: N_{2}: N_{3}\right)$ are the winding ratios of the coupled inductor.

A comparison between the inductors, the capacitors design, voltage and current ripples for the three converters is shown in Table I. 
TABLE I. Component design for the Boost, Z-source and Y-source converters

\begin{tabular}{|l|c|c|c|}
\hline Components & Boost & Z-source & Y-source \\
\hline $\begin{array}{l}\text { Current ripple across } \\
\text { inductor }\end{array}$ & $\Delta I_{L}=0.2 \times \frac{P_{\text {out }}}{V_{\text {in }}}=20 \% I_{L}$ & $\Delta I_{L}=20 \% I_{L}$ & $\Delta I_{L}=20 \% I_{M}$ \\
\hline $\begin{array}{l}\text { Voltage ripple across } \\
\text { capacitor }\end{array}$ & $\Delta V_{C_{\text {out }}}=2 \% V_{\text {out }}$ & $\Delta V_{C}=2 \% V_{\text {out }}$ & $\Delta V_{C_{\text {out }}}=2 \% V_{\text {out }}$ \\
\hline Inductor equation & $L=\frac{V_{\text {in }} \times D}{\Delta I_{L} \times f_{s}}$ & $L=L_{1}=L_{2}=\frac{T_{o} \times V_{c}}{\Delta I_{L}}$ & $L_{N}=A_{L} N^{2} 10^{-3}, L_{\text {lik }}=\frac{0.292 \times N^{1.056} \times A_{c}}{L_{c}}$ \\
\hline Capacitor equation & - & $C=C_{1}=C_{2}=\frac{T_{o} \times I_{L}}{V_{c} \times \% \Delta V_{c}}$ & $L_{N}+L_{\text {lik }}$ \\
& $C_{\text {out }}=\frac{I_{\text {out (max }} \times D}{f_{s} \times \Delta V_{\text {out }}}$ & $C_{\text {out }}=\frac{V_{\text {out }} \times D}{R_{l} \times f_{s} \times \Delta V_{\text {out }}}$ & $\frac{\mathrm{d}_{\mathrm{ST}}}{2 \%(1-D) \mathrm{f}_{\mathrm{s}}}$ \\
& & $\left.\frac{V_{\text {out }} \times D}{1-\mathrm{k} \mathrm{D}}-1\right) \frac{\mathrm{P}_{\mathrm{o}}}{\mathrm{V}_{\mathrm{o}}^{2}}$ \\
\hline
\end{tabular}

$\mathrm{I}_{\mathrm{M}}$ : Magnetizing current, $\mathrm{L}_{\mathrm{N}}$ : Nominal inductance, $\mathrm{L}_{\mathrm{lik}}$ : leakage inductance, $\mathrm{T}_{\mathrm{o}}=\mathrm{DT}=\mathrm{D} / \mathrm{f}_{\mathrm{sw}}$

\section{EVALUATION OF POWER LOSSES AND THERMAL PERFORMANCE}

In this section, the formulas for calculating the relevant power losses are presented. PLECS toolbox is used for the three converter analysis. The parameters selected for each converter are compared according to the passive components counts and their voltage and current ripples are as shown in Table I. The same for the switching devices, which are designed according to each converter requirements for the voltage and current ratings for a realistic comparison.

\section{A. Switching and conduction losses calculations}

Switching losses occur when the device is transitioning from the blocking state to the conducting state and vice-versa. This interval is characterized by a significant voltage across its terminals and a significant current through it. The energy dissipated in each transition needs to be multiplied by the switching frequency to obtain the switching losses;

The switching losses $P_{s w}$ are expressed in (5) as:

$$
P_{s w}=\left(E_{o n}+E_{o f f}\right) \times f_{s w}
$$

where $E_{o n}$ and $E_{o f f}$ are the energy losses during turn on and turn off of the switch, $f_{s w}$ is the switching frequency.

Conduction losses occur when the device is in full conduction mode. These losses are in direct relationship with the duty cycle.

The average conduction losses $P_{\text {cond }}$ are expressed in (6) as:

$$
P_{\text {avg.cond }}=\frac{1}{T} \int_{0}^{T}\left[v_{c e}(t) \times i_{c e}(t)\right] d t
$$

where $v_{c e}$ is the on state voltage, an $i_{c e}$ is the on state current. The time period $T$ is as given in (7):

$$
T=\frac{1}{f_{s w}}
$$

where $f_{s w}$ is inversely proportional to the time period $T$.

\section{B. Capacitor ESR losses calculations}

The Capacitor Equivalent Series Resistance (ESR) is the value of the resistance, which is equal to the total effect of a large set of energy loss mechanisms occurring under the operating conditions where it can be a parameter to measure the capacitor losses. The capacitor losses are expressed in (8) as:

$$
P_{\text {cap.loss }}=I_{\text {cap. }}^{2} \times E S R
$$

where $I_{\text {cap }}$. is the rms current passing through the capacitor, and $E S R$ is the equivalent series resistance measuring the effect of the losses dissipated in the capacitor.

\section{Winding and core losses calculations}

According to the Steinmetz's equation, which is a physics based equation used to calculate the core loss of magnetic materials due to hysteresis. The core losses are expressed in (9):

$$
P_{v}=k f^{\alpha} \hat{B}^{\beta}
$$

where $\hat{B}$ is the peak flux density excitation with frequency $f, P_{v}$ is the time-average power loss per unit volume, and $(\alpha, \beta, k)$ are the material parameters found by curve fitting.

The improved generalized Steinmetz's equation is expressed in (10):

$$
P_{v}=\frac{1}{T} \int_{0}^{T} k_{i}\left|\frac{d B}{d t}\right|^{\alpha}\left(\Delta B^{\beta-\alpha}\right) d t
$$


where $\Delta B$ is the flux density from peak to peak and in (11):

$$
k_{i}=\frac{k}{(2 \pi)^{\alpha-1} \int_{0}^{2 \pi}|\cos \theta|^{\alpha} \times 2^{\beta-\alpha} d \theta}
$$

where $\theta$ is the angle of the sinusoidal waveform simulated.

The copper losses in the winding describe the energy dissipated by the resistance in the wire used in the coil. It is divided in to 2 types (DC and AC winding loss). The DC winding losses can be calculated in (12) as:

$$
P_{D C}=I_{a v}^{2} \times R_{D C}
$$

where $\left(P_{D C}\right)$ is the DC copper losses in the winding, $I_{a v}$ is the average current passing through the wire, and $R_{D C}$ is the $\mathrm{DC}$ resistance of the wire.

AC copper losses can be significant for large current ripple and for higher frequency. It can be calculated through the skin effect, where the current density is an exponentially decaying function of the distance into the wire, with the characteristic length $\delta$ is known as the skin depth in (13) as:

$$
\delta=\frac{7.5}{\sqrt{f_{s}}}
$$

where $\delta$ is the skin depth in $\mathrm{cm}$, and $f_{s}$ is the switching frequency which in our design is $20 \mathrm{kHz}$.

In order to calculate the $\mathrm{AC}$ resistance $R_{A C}$, the thickness $h$ of the wire should be known since it is a function of the dc resistance $R_{D C}$ which can be calculated in (14):

$$
R_{A C}=\frac{h}{\delta} \times R_{D C}
$$

where $h$ is the thickness of the wire in $\mathrm{cm}$.

The AC winding losses can be calculated as given in (15) as:

$$
P_{A C}=I_{A C-r m s}^{2} \times R_{A C}
$$

where $P_{A C}$ is the AC winding loss, $I_{A C-r m s}$ is AC ripple rms current passing through the wire, and $R_{A C}$ is the AC winding resistance.

\section{Magnetic core design calculations}

In this section, the magnetic core design [14] is illustrated through the following steps:

1) In order to select a proper core size, the DC current $I_{D C}$ in Ampere and the inductance $L$ in mili Henry required with DC bias should be known to select the core from the core selector chart according to the calculated value $\left(\mathrm{mH} . \mathrm{A}^{2}\right)$ in (16):

$$
L I_{D C}^{2}=\text { value }
$$

A high flux 58337 core [14] was selected for the 3 converters in order to have fair comparison from an efficiency point of view for the voltage gain of 2 .
2) Inductance, core size and permeability are now known, then calculating the number of turns by determining the minimum inductance factor $A_{L \min }$ by using the worst case negative tolerance (generally $-8 \%$ ) given in the core data sheet in (17) and (18)

$$
\begin{gathered}
A_{\text {lmin }}=A_{l}-0.08 \mathrm{Al} \\
N=\sqrt{\frac{L \times 10^{3}}{A_{l \text { min }}}}
\end{gathered}
$$

where $A_{l}$ is the inductance factor found in the core data sheet $\left(\mathrm{nH} / \mathrm{T}^{2}\right), A_{l \min }$ is the minimum inductance factor $\left(\mathrm{nH} / \mathrm{T}^{2}\right)$, and $L$ is the inductance in $(\mu \mathrm{H})$.

3) Choosing the suitable wire size according to rated power and calculated number of turns $(N)$, is the last step before calculating the DC resistance according to the wire size with window fill assumed to be $40 \%$ in (19) as:

$$
C_{A}=\frac{W_{f} \times W_{A}}{N}
$$

where $C_{A}$ is the wire area, $W_{f}$ in the window fill, and $N$ is the no. of turns.

4) The DC resistance can be estimated after knowing the winding factor of the core, wire gauge (AWG), and the number of turns. The DC resistance can be calculated in (20) as:

$$
R_{D C}=M L T \times N \times \Omega / \text { Length }
$$

where $M L T$ is the mean length per turn, and $\Omega /$ Length is the resistance per meter.

Furthermore, in the voltage gain of 4 METGLAS power-lite C-core [15] is used and $K_{g}$-method is applied [16]

\section{Simulation Results AND Discussion}

In this section, different power loadings for the voltage gain equal to 2 and 4 are presented in order to demonstrate a fair comparison between the 3 topologies with respect to the thermal performance and the losses (switching, conduction, capacitor ESR losses, core and winding losses) for calculating the efficiency of each converter. Thermal and efficiency investigation are presented in a separate subsection. Table II summarizes the specifications and the requirements used in the simulation results.

The design specifications for each voltage gain are given separately for each topology as it can be seen from Table III, which summarize the semiconductor devices average current and voltage ratings used in the 3 converters. These ratings are based on the required voltage gain for each converter separately.

\section{A. Junction temperature investigation of the switch under different power loading}

For each semiconductor a heat sink has been designed. A maximum junction temperature of $125{ }^{\circ} \mathrm{C}$ has been used a design constraint. The estimation of the junction temperature 
TABLE II. Common specifications and simulation parameters for the Boost, Z-source and Y-source converters

\begin{tabular}{|c|c|c|c|c|}
\hline \multicolumn{5}{|c|}{ Common converter specifications for gain 2 and 4} \\
\hline \multicolumn{2}{|c|}{ Maximum Power rating } & \multicolumn{3}{|c|}{$20 \mathrm{~kW}$} \\
\hline \multicolumn{2}{|c|}{ Input voltage $V_{\text {in }}$} & \multicolumn{3}{|c|}{$200 \mathrm{~V} \backslash 100 \mathrm{~V} *$} \\
\hline \multicolumn{2}{|c|}{ Output voltage $V_{\text {out }}$} & \multicolumn{3}{|c|}{$400 \mathrm{~V}$} \\
\hline \multicolumn{2}{|c|}{ Switching frequency $f_{s}$} & \multicolumn{3}{|c|}{$20 \mathrm{kHz}$} \\
\hline \multicolumn{2}{|c|}{ Resistive load $R_{1}$} & \multicolumn{3}{|c|}{$8 \Omega$} \\
\hline \multicolumn{2}{|c|}{ Maximum junction temperature $T_{j \text {-max. }}$} & \multicolumn{3}{|c|}{$125^{\circ} \mathrm{C}$} \\
\hline \multicolumn{2}{|c|}{ Simulation parameters } & Boost & Z-source & Y-source \\
\hline \multirow{3}{*}{ Gain 2} & Duty cycle $D$ & 0.5 & 0.25 & 0.167 \\
\hline & No. of turns & 64 & 55 & $(32: 32: 64)$ \\
\hline & Switch RMS current & $71 \mathrm{~A}$ & $100 \mathrm{~A}$ & $120 \mathrm{~A}$ \\
\hline \multirow{3}{*}{ Gain 4} & Duty cycle $D$ & 0.75 & 0.375 & 0.25 \\
\hline & No. of turns & 27 & 30 & $(7: 7: 14)$ \\
\hline & Switch RMS current & $171 \mathrm{~A}$ & $237 \mathrm{~A}$ & $346 \mathrm{~A}$ \\
\hline
\end{tabular}

* Input voltage for gain 4

TABLE III. Semiconductor devices selection for the three converters and their different voltage gains.

\begin{tabular}{|c|c|c|c|}
\hline Converter & Semiconductor devices & Gain 2 & Gain 4 \\
\hline \multirow{2}{*}{ ஜ̊: } & IGBT & $\begin{array}{l}\text { (IXXX200N60C3) } \\
600 \mathrm{~V} \text { and } 200 \mathrm{~A}\end{array}$ & $\begin{array}{l}\text { (MG06600WB-BN4MM) } \\
600 \mathrm{~V} \text { and } 600 \mathrm{~A}\end{array}$ \\
\hline & Diode $\left(\mathrm{D}_{1}\right)$ & $\begin{array}{l}\text { (IDW100E60) } \\
600 \mathrm{~V} \text { and } 100 \mathrm{~A}\end{array}$ & $\begin{array}{l}\text { (DB2F200N/P6S) } \\
600 \mathrm{~V} \text { and } 200 \mathrm{~A} \\
\end{array}$ \\
\hline \multirow{3}{*}{ 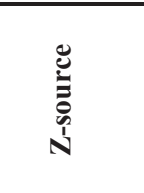 } & IGBT & $\begin{array}{l}\text { (MG06400D-BN4MM) } \\
600 \mathrm{~V} \text { and } 400 \mathrm{~A}\end{array}$ & $\begin{array}{l}\text { (MG06600WB-BN4MM) } \\
600 \mathrm{~V} \text { and } 600 \mathrm{~A}\end{array}$ \\
\hline & Diode $\left(\mathrm{D}_{1}\right)$ & $\begin{array}{l}\text { (DS1F300N6S ) } \\
600 \mathrm{~V} \text { and } 300 \mathrm{~A} \\
\end{array}$ & $\begin{array}{l}\text { (SD600N/R Series) } \\
\text { 600V and 600 A }\end{array}$ \\
\hline & Diode $\left(\mathrm{D}_{2}\right)$ & $\begin{array}{l}\text { (DS1F300N6S ) } \\
\text { 600V and 300 A } \\
\end{array}$ & $\begin{array}{l}\text { (DS1F300N6S) } \\
600 \mathrm{~V} \text { and } 300 \mathrm{~A} \\
\end{array}$ \\
\hline \multirow{3}{*}{ 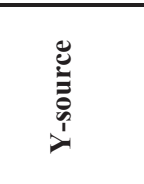 } & IGBT & $\begin{array}{l}\text { (MG06600WB-BN4MM) } \\
600 \mathrm{~V} \text { and } 600 \mathrm{~A}\end{array}$ & $\begin{array}{l}\text { (MG06600WB-BN4MM) } \\
600 \mathrm{~V} \text { and } 600 \mathrm{~A}\end{array}$ \\
\hline & Diode $\left(\mathrm{D}_{1}\right)$ & $\begin{array}{l}\text { (VSK.9112 ) } \\
1200 \mathrm{~V} \text { and } 100 \mathrm{~A}\end{array}$ & $\begin{array}{l}\text { (SKN 501/12 Semikron) } \\
1200 \mathrm{~V} \text { and } 720 \mathrm{~A}\end{array}$ \\
\hline & Diode $\left(\mathrm{D}_{2}\right)$ & $\begin{array}{l}\text { (DS1F300N6S ) } \\
600 \mathrm{~V} \text { and } 300 \mathrm{~A}\end{array}$ & $\begin{array}{l}\text { (DS1F300N6S) } \\
600 \mathrm{~V} \text { and 300 A }\end{array}$ \\
\hline
\end{tabular}

of the switches are done according to the thermal model and the mapped losses using the PLECS toolbox. The estimation of the junction temperatures are different for the 3 topologies, since the desired thermal resistance of the heat sink is not the exact calculated value found in the manufactured heat sinks.

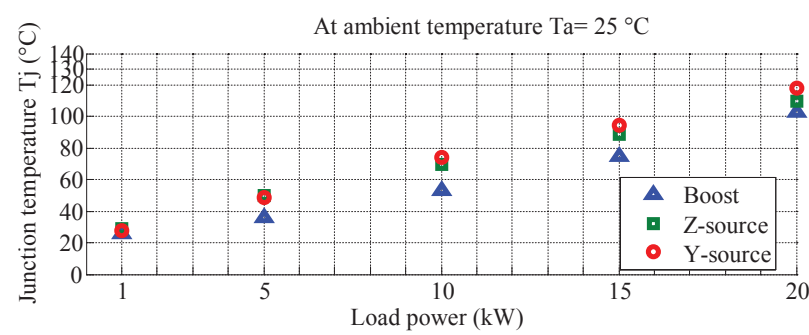

Fig. 6. Junction temperature variation of the switch at different power loading and using a voltage gain of 2 .

In this case, the load power is varying from 1 to $20 \mathrm{~kW}$, and a constant ambient temperature is assumed which is 25 ${ }^{\circ} \mathrm{C}$. The junction temperature variation results of the compared

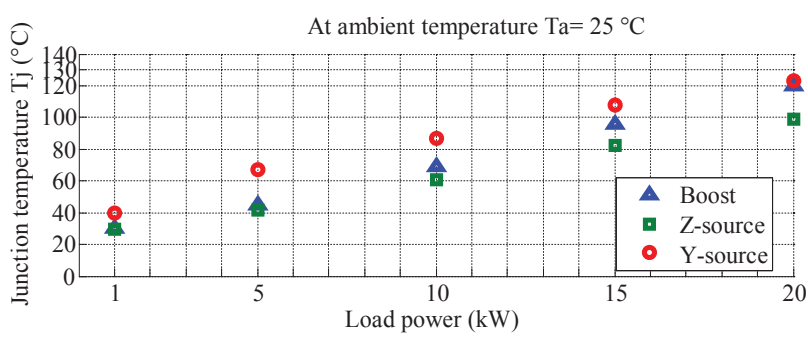

Fig. 7. Junction temperature variation of the switch at different power loading and using a voltage gain of 4 .

topologies are shown in Fig. 6 for voltage gain of 2. Fig. 7 shows the junction temperature variation at different loading power for voltage gain of 4 .

\section{B. Efficiency investigation under different power loading}

In this subsection the efficiency is calculated according to the total power losses for each converter as listed in the beginning of section IV using the same conditions listed in 
TABLE IV. Distribution of the different losses for the Boost converter at $20 \mathrm{~kW}$ load power and two different voltage gain.

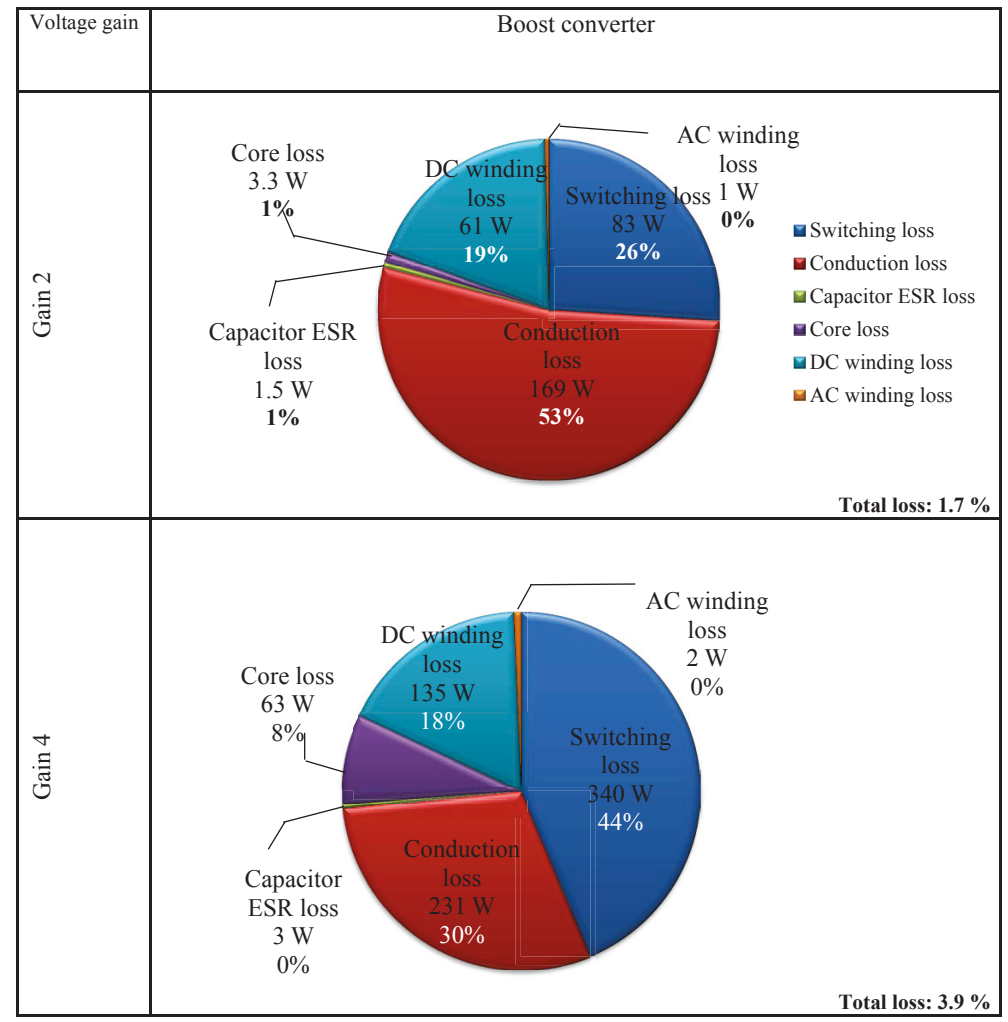

TABLE V. Distribution of the different losses for the Z-source converter at $20 \mathrm{~kW}$ load power and two different voltage gain.

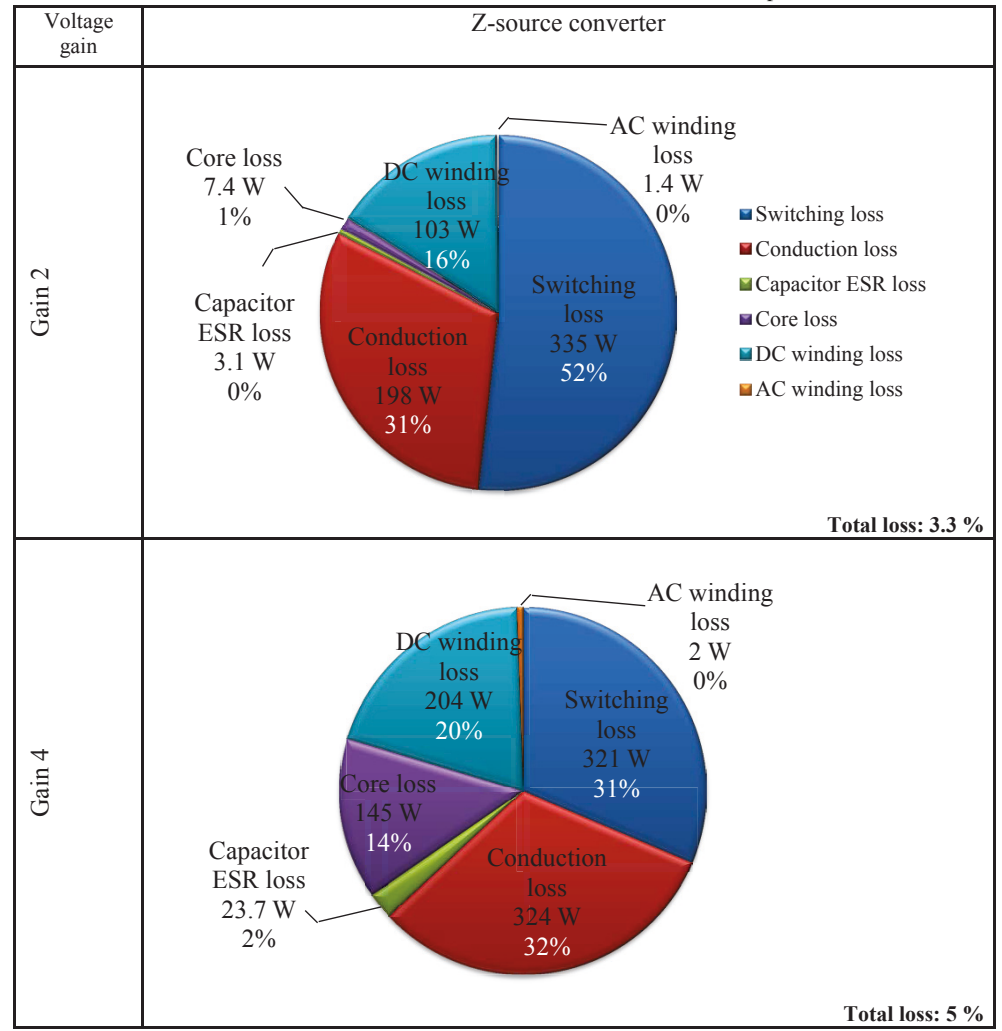


TABLE VI. Distribution of the different losses for the Y-source converter at $20 \mathrm{~kW}$ load power and two different voltage gain.

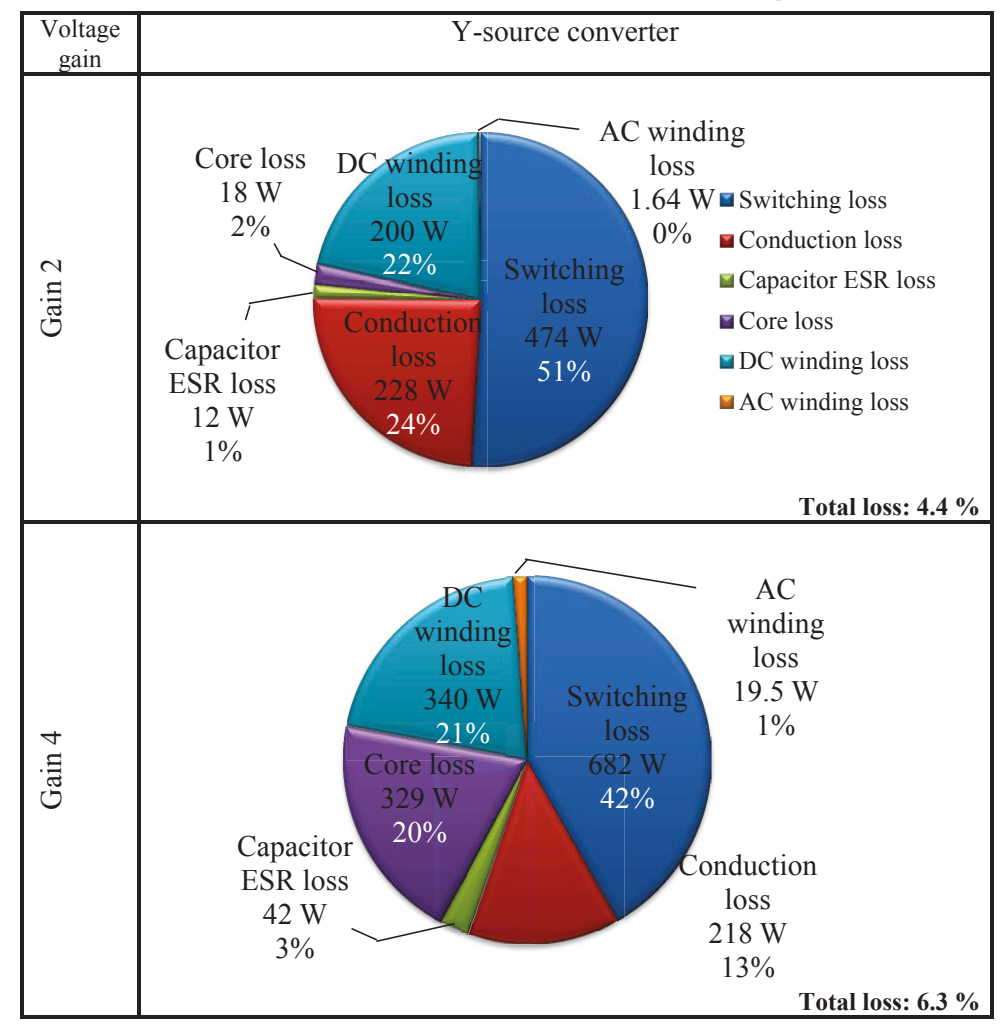

Table II. The results in Fig. 8 show that the boost converter has the highest efficiency of $98 \%$ compared with the Y-source converter of $96 \%$ and the Z-source converter of $96.7 \%$ at 20 $\mathrm{kW}$ loading power. The measured efficiencies from low power loading $(1 \mathrm{~kW})$ to higher power loading $(20 \mathrm{~kW})$ is also shown in 8 . the same analysis is repeated for voltage gain of 4 as shown in 9.

At ambient temperature $\mathrm{Ta}=25^{\circ} \mathrm{C}$

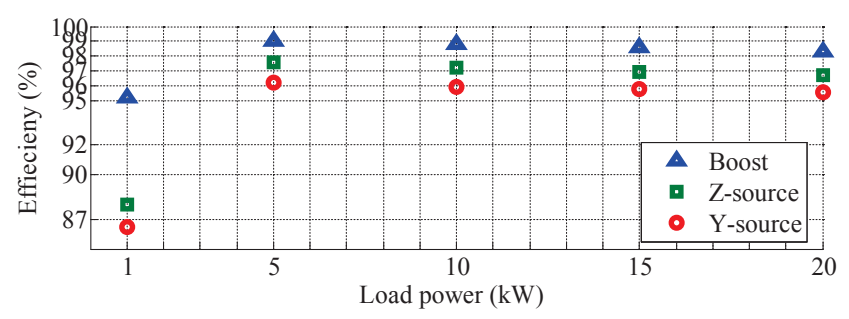

Fig. 8. The efficiency at different loading power and using a volatge gain of 2 .

\section{Total losses at $20 \mathrm{~kW}$ power loading}

In this section a better understanding is given for the efficiency and loss mapping. Six pie charts are presented in Tables IV, V, and VI for the same power loading $20 \mathrm{~kW}$ and different voltages gain (2 and 4). The total loss listed in Table $\mathrm{IV}, \mathrm{V}$, and VI were calculated from the total power loss of each converter by measuring the total efficiency as summarized in

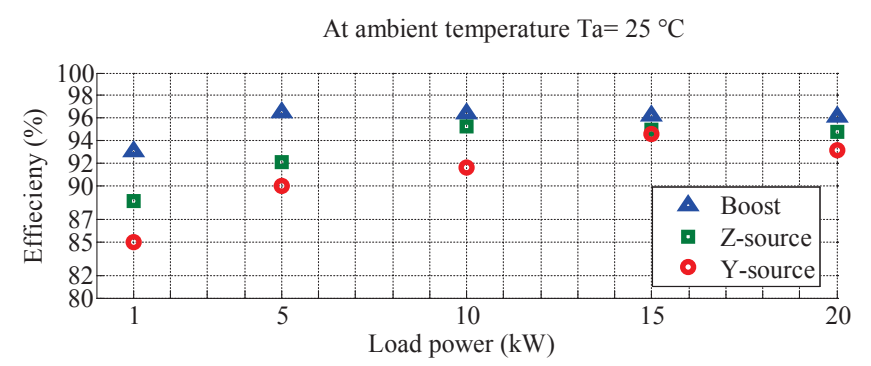

Fig. 9. The efficiency at different loading power and using a volatge gain of 4.

Table VIII. The switching and the conduction losses are the total losses generated from the semiconductor devices (switch and diodes). In Table VIII comparison of the total efficiencies using voltage gains of 2 and 4 for the compared converters at $20 \mathrm{~kW}$ load power.

In voltage gain 2, the magnetic losses which in the Y-source converter is sharing $34 \%$ of the total losses is the double percentage of the magnetic losses in the Z-source converter and 1.5 times the percentage in the boost converter. The capacitor losses in percentages are almost the same in the 3 converters. The switching and conduction losses are the lowest in the boost converter compared to the Z- source and Y-source converters. The switching and the conduction losses are varied based on the semiconductor devices ratings, as these devices are designed according to the required voltage gain, converter 
specifications, and to withstand the maximum ratings of each operated converter.

In the voltage gain 4 case, the magnetic losses in the Ysource is sharing $42 \%$ of the total losses is more than double the percentage of the magnetic losses in the boost converter and 1.2 times the percentage in the Z-source converter.

TABLE VII. Comparison of the total efficiencies using gain 2 and gain 4 for
converters at $20 \mathrm{~kW}$ load.
\begin{tabular}{|c|c|c|c|}
\hline Efficiency & Boost & Z-source & Y-source \\
\hline Gain 2 & $98.3 \%$ & $96.7 \%$ & $95.6 \%$ \\
\hline Gain 4 & $96.1 \%$ & $95 \%$ & $93.7 \%$ \\
\hline
\end{tabular}

\section{CONCLUSIONS}

In this paper a comparison between the Y-source, Z-source and the conventional boost converter has been performed with respect to their thermal behaviour and efficiency. Different loading conditions between $1 \mathrm{~kW}$ and $20 \mathrm{~kW}$ are considered during the studies of the efficiency and junction temperature of the converters for two different voltages gain ( 2 and 4$)$. The junction temperature variation in voltage gain of 4 is higher than the junction temperature variation in voltage gain of 2 .

Investigations on both the magnetic and electrical losses are also given. The magnetic losses which in the Y-source converter is sharing $34 \%$ and $42 \%$ of the total losses in voltage gain of 2 and 4 receptivity which is higher than in the boost and Z-source converters. In the electrical losses it can be noticed that the total electrical loss for voltage gain of 4 is lower than for voltage gain of 2 which clarify that having higher current ratings devices improve the efficiency. This paper summarizes the comparison between the type of losses at constant loading condition. The thermal performances are quite similar in the 3 converters for both voltage gains. The boost converter has better efficiencies in the two selected voltage gains, but it has also the highest decrease in the efficiency from gain 2 to gain 4 at $20 \mathrm{~kW}$ power loading compared with the Z-source and Y-source converters.

\section{REFERENCES}

[1] S. Yang, D. Xiang, A. Bryant, P. Mawby, L. Ran, and P. Tavner, "Condition monitoring for device reliability in power electronic converters: A review," IEEE Trans. on Power Electronics, vol. 25, no. 11, pp. 2734-2752, Nov. 2010.

[2] H. Chung, H. Wang, F. Blaabjerg, and M. Pecht, Reliability of Power Electronics Converter Systems. The Institution of Engineering and Technology (IET), Dec. 2015.

[3] K. Ramtek and Y. Nagpur, "Dynamic modelling and controller design for z-source dc-dc converter," International Journal of Scientific Engineering and Technology, vol. 2, no. 4, pp. 272-277, Apr. 2013.
[4] F. Z. Peng, M. Shen, and Z. Qian, "Maximum boost control of the z-source inverter," in Proc. of IEEE 35th Annual Power Electronics Specialists Conference (PESC), vol. 1, June 2004, pp. 255-260 Vol.1.

[5] Y. Siwakoti, P. C. Loh, F. Blaabjerg, and G. Town, "Ysource impedance network," in Proc. of 29th Annual IEEE Applied Power Electronics Conference and Exposition (APEC), March 2014, pp. 3362-3366.

[6] Y. Siwakoti, P. C. Loh, F. Blaabjerg, S. Andreasen, and G. Town, "Y-source boost $\mathrm{dc} / \mathrm{dc}$ converter for distributed generation," IEEE Trans. on Industrial Electronics, vol. 62, no. 2, pp. 1059-1069, Feb 2015.

[7] B. Gadalla, E. Schaltz, Y. Siwakoti, and F. Blaabjerg, "Investigation of efficiency and thermal performance of the y-source converters for a wide voltage range," Journal of Renewable Energy and Sustainable Development, vol. 1, no. 2, pp. 300-305, Jan. 2016.

[8] Y. Siwakoti, F. Z. Peng, F. Blaabjerg, P. C. Loh, and G. Town, "Impedance-source networks for electric power conversion part i: A topological review," IEEE Trans. on Power Electronics, vol. 30, no. 2, pp. 699-716, Feb 2015.

[9] F. Z. Peng, "Z-source inverter," IEEE Trans. on Industry Applications, vol. 39, no. 2, pp. 504-510, Mar 2003.

[10] W. T. Franke, M. Mohr, and F. W. Fuchs, "Comparison of a $\mathrm{z}$-source inverter and a voltage-source inverter linked with a dc/dc-boost-converter for wind turbines concerning their efficiency and installed semiconductor power," in Proc. of IEEE Power Electronics Specialists Conference (PESC), June 2008, pp. 1814-1820.

[11] N. Baker, M. Liserre, L. Dupont, and Y. Avenas, "Improved reliability of power modules: A review of online junction temperature measurement methods," IEEE Industrial Electronics Magazine, vol. 8, no. 3, pp. 17-27, Sept 2014.

[12] B. Gadalla, E. Schaltz, Y. Siwakoti, and F. Blaabjerg, "Thermal performance and efficiency investigation of conventional boost, z-source and y-source converters," in IEEE 16th International Conference on Environment and Electrical Engineering (EEEIC), June 2016, pp. 1-6.

[13] D. J. S. Newlin, R. Ramalakshmi, and S. Rajasekaran, “A performance comparison of interleaved boost converter and conventional boost converter for renewable energy application," in International Conference on Green High Performance Computing (ICGHPC), March 2013, pp. 16.

[14] Magnetics. Magnetics powder core catalog. [Online]. Available: http://www.mag-inc.com/company/ news/new-powder-core-catalog

[15] Metglas. Powerlite inductor cores. [Online]. Available: http://www.elnamagnetics.com/wp-content/ uploads/catalogs/metglas/powerlite.pdf

[16] R. W. Erickson and D. Maksimovic, Fundamentals of Power Electronics, Second Edition. Springer Science + Bussiness Media, LLC, May 2001. 